\title{
On a Ventilator in Shackles
}

\author{
Amar D. Bansal, $M D^{7}$ and Lawrence A. Haber, $\mathrm{MD}^{2}$ (]) \\ 'Department of Medicine, Renal Electrolyte Division, University of Pittsburgh, Pittsburgh, PA, USA; ${ }^{2}$ Department of Medicine, Division of Hospital \\ Medicine, San Francisco General Hospital and Trauma Center, University of California, San Francisco, CA, USA.
}

$\mathrm{J}$ Gen Intern Med 36(12):3878-9

DOI: $10.1007 / \mathrm{s} 11606-021-07097-6$

(c) Society of General Internal Medicine 2021

A pproaching the back corner of the intensive care unit, two uniformed correctional officers sat outside my patient's room. As a nephrologist, I had been consulted for renal failure stemming from the patient's COVID-19-related acute respiratory distress syndrome. Scenes of prisoners with severe pulmonary infections were unfolding rapidly across the country since congregate settings, such as prisons, had become hotspots during the pandemic. ${ }^{1}$ Turning towards the glass doors, I saw a familiar set of monitors and a patient, lying prone, attached to a ventilator.

Then I saw the shackle. The dusky, angular steel clasped to the man's right ankle stood in sharp contrast to the smooth white sheets of his hospital bed. Adjacent to the heavy cuff and chain ran clear medical tubing delivering life-sustaining vasopressors and paralytics to his limp, hypoxemic body. The guards scrolled silently through their phones in the hallway.

I leaned back abruptly, as if stumbling on a crime scene, and stared at the shackle. The patient could not move; he was dependent on medications to support his blood pressure, a ventilator to breathe, and blood would soon flow through a machine in the absence of working kidneys. The ratchet teeth of the shackle's cuff closed in on my thoughts while I wrote the required dialysis orders. I hurried to another unit to continue rounds, but no longer felt I was in the business of healing.

The patient was a Black man, and I imagined that at some point, during his impending respiratory failure, he had mouthed the words, "I can't breathe." I imagined the shackle was there when he first began to feel short of breath, already far from being able to mount an escape or harm others. It was there when he was intubated and placed on a ventilator. And it was still there, while he lay face down and paralyzed, his organs failing.

I was transported to the spring George Floyd was killed. I cried then while watching evening news footage of a police officer kneeling on Mr. Floyd's neck as he lay face down on the sidewalk in handcuffs, also unable to breathe. The

Received July 26, 2021

Accepted August 10, 2021

Published online September 7, 2021 chanting from peaceful demonstrations nearby pulsed into our home as my children slept. No such crowds gathered outside my patient's room. Tears came again, this time in a lonely corridor between hospital units.

The following day, I mustered the courage to discuss the patient's shackle with a colleague. I prefaced the discussion by stating that my question was not about electrolytes or urine output before inquiring if we could remove his shackle. The force being applied to control the unconscious man seemed disproportionate to his ability to escape or harm others. I was expecting consensus that chaining someone critically ill on a ventilator to the hospital bed was not simply unnecessary, it was inhumane.

The colleague explained that we were following protocol and cited anecdotes of prisoners pretending to be sick so they could come to the hospital to escape their sentence and of others committing crimes while under hospital care. Though we knew little about the patient other than his medical history, the metal restraint was necessary for everyone's safety. The prejudgment precipitated by the shackle preceded any facts about the person or the situation at hand.

Systemic racism remains divisive because many view it as a fabrication. Over-policing and mass incarceration have led to Black prisoners being disproportionately represented in jails and prisons. ${ }^{2}$ Those of us in positions of power may disregard the shackle, or not question its purpose, or even propose that it is justified. Shackles can cause direct harm by compressing underlying skin and soft tissues ${ }^{3}$ and indirect harm by decreasing our empathy towards incarcerated patients. ${ }^{4}$ Despite legislative progress, shackles can still be found in hospitals when female prisoners are giving birth and when dying prisoners are taking their last breaths. ${ }^{5}$

Yet the shackle also reminded me of one of the most joyful days I have had as a physician, at the White Coats for Black Lives event held last summer across medical schools nationally. Surrounded by practitioners, from students to division chiefs, I felt empowered as we knelt on the hospital lawn for 8 minutes 46 seconds, fists raised in solidarity. Alongside broader social justice movements, change is happening at smaller levels in medicine. In my subspecialty, we are undergoing a reexamination of the intersection of race and biology, with a focus on abandoning race-adjusted estimations of kidney function. ${ }^{6}$

These waves of optimism had been helping me heal, but progress is rarely linear. Seeing the patient prone in shackles 
opened wounds precipitated by the killing of Mr. Floyd that would never close. I provided the medical care required in the moment, but the shackle remained. With inaction, I felt complicit in the larger problem and the change that seemed possible together felt elusive alone. The shackling of unconscious patients reveals how the prejudice and violence harming people of color in our communities permeates our hospital beds. There is no medical or legal justification for a patient who is sedated, paralyzed, and unable to breathe to still lie in bondage.

Acknowledgements: The authors would like to acknowledge Dr. Brie Williams for her expertise and review of this manuscript.

Corresponding Author: Lawrence A. Haber, MD; Department of Medicine, Division of Hospital Medicine, San Francisco General Hospital and Trauma Center, University of California, San Francisco, CA, USA (e-mail: Lawrence.haber@ucsf.edu).

\section{Declarations:}

Conflict of Interest: The authors report no conflicts of interest.

\section{REFERENCES}

1. Barsky BA, Reinhart E, Farmer P, Keshavjee S. Vaccination plus Decarceration- Stopping Covid-19 in Jails and Prisons. New Engl J Med. Published online 2021. https://doi.org/10.1056/nejmp2100609

2. Carson EA. Prisoners in 2019. US Department of Justice, Office of Justice Programs, Bureau of Justice Statistics. https://www.bjs.gov/content/ pub/pdf/p19.pdf. Accessed May 18, 2021.

3. Haber LA, O'Brien M. Shackling Ulcer: an Upper Extremity Ulcer Secondary to Handcuffs. J Gen Intern Med. 2021 Feb 24. doi: https:// doi.org/10.1007/s11606-021-06654-3.Epubaheadofprint.

4. Haber LA, Erickson HP, Ranji SR, Ortiz GM, Pratt LA. Acute Care for Patients Who Are Incarcerated: A Review. JAMA Intern Med. 2019;179(11):1561-1567. doi:https://doi.org/10.1001/jamainternmed. 2019.3881.

5. DiTomas M, Bick J, Williams B. Shackled at the End of Life: We Can Do Better. Am J Bioeth. 2019;19(7):61-63. doi:https://doi.org/10.1080/ 15265161.2019.1618957

6. Diao JA, Inker LA, Levey AS, Tighiouart H, Powe NR, Manrai AK. In Search of a Better Equation- Performance and Equity in Estimates of Kidney Function. New Engl J Med. 2021;384(5):396-399. doi:https://doi. org/10.1056/nejmp2028243

Publisher's Note: Springer Nature remains neutral with regard to jurisdictional claims in published maps and institutional affiliations. 